\title{
Journal of Solid Mechanics and Materials Engineering (JSMME): a New, Free Accessible E-Journal
}

The Journal of Solid Mechanics and Materials Engineering is a new, free accessible e-journal, which is edited and managed jointly by the Materials and Mechanics Division (MMD) and the Materials and Processing Division (MPD) of the Japan Society of Mechanical Engineering (JSME). The Journal is published using the electronic system J-STAGE available for free at the website hosted by the Japan Science and Technology Agency. The Journal contains original research papers, short papers and review articles in the fields of Mechanics of Solids and Structures, Strength and Deformation Behavior of Materials, Development and Characterization of Engineering Materials, and Materials Manufacturing and Processing. The content of the Journal thus reflects the current state of the disciplines and arts concerned with the research activities of the two Divisions.

The new journal has the following background. The Society earlier published an English journal, JSME International Journal, which has been slated for improvements so as to respond to the growing diversity and globalization of the needs of JSME members. The Board of JSME thus established a committee in 2002 to enhance journal publication, in the course of which it was finally decided to discontinue the JSME International Journal in favor of having each division of JSME publish its own electronic journal. This decision was discussed independently in the Materials and Mechanics Division and the Materials and Processing Division in 2005, eventually leading to the publication of a new electronic journal edited and managed jointly by the two Divisions. Papers have been then called since June 1, 2006, for the new journal to appear in 2007.

The editors believe that the Journal will contribute to developments in the fields related to the research activities of the two Divisions. We would like to thank Professor Keiichiro Tohgo for his great effort devoted to planning the Journal in 2005.

Nobutada Ohno

Editor-in-Chief

Materials and Mechanics Division

Toshihiko Mori

Editor-in-Chief

Materials and Processing Division 